\title{
Monomeric carbohydrate uptake and structure-function coupling in stream biofilms
}

\author{
Gabriel Singer ${ }^{1,2}$, Katharina Besemer ${ }^{1,2}$, Gerald Hochedlinger ${ }^{1}$, Ann-Kathrin Chlup ${ }^{1}$, \\ Tom J. Battin ${ }^{1,2, *}$
}

${ }^{1}$ Department of Limnology, University of Vienna, 1090 Vienna, Austria

${ }^{2}$ WasserCluster Biologische Station Lunz GmbH, 3293 Lunz am See, Austria

\begin{abstract}
We investigated the uptake of monomeric carbohydrates in stream biofilms under various hydrodynamic environments. Flow velocity and biofilm structure influenced the uptake of glucose (Glc) and arabinose (Ara), 2 carbohydrate monomers differing in bioavailability. While the uptake of Glc increased with flow velocity, the uptake of Ara showed a weaker and inverse relationship with flow velocity. Microautoradiography and confocal-laser-scanning-microscopy of biofilm cryosections revealed patterns of monomer uptake over biofilm depth. Glc was preferentially taken up in the biofilm canopy, and modelled depth gradients suggested that boundary layer thickness controls external Glc mass transfer to the biofilm. In contrast, Ara uptake was uniformly distributed or concentrated in deeper biofilm layers. Overall, Glc uptake was negatively correlated with Ara uptake. We suggest that the spatial separation of monomer uptake involves unidirectional supply flux to biofilms and selective use of carbon sources of differing quality. This 'metabolic stratification' can be interpreted as an expression of the long-known carbon catabolite repression phenomenon initially described as 'diauxie' by Jacques Monod in 1942.
\end{abstract}

KEY WORDS: Stream · Carbohydrate monomer · Hydrodynamics · Biofilm · Carbon catabolite repression $\cdot$ Mass transfer $\cdot$ Diauxie

\section{INTRODUCTION}

Metabolism of organic carbon in streams and rivers has recently been identified as responsible for a large amount of $\mathrm{CO}_{2}$-outgassing to the atmosphere (Cole 2007, Battin et al. 2008, 2009). Dissolved organic carbon (DOC), the largest pool of organic carbon in aquatic ecosystems (Wetzel 1992), is composed of a wide diversity of polymeric and monomeric compounds from various sources and of varying bioavailability (Thurman 1985, Kaplan \& Newbold 2003, Hertkorn et al. 2008). The bioavailability of DOC depends on intrinsic compound-specific properties related to molecular structure or elemental composition (Sun et al. 1997, Frazier et al. 2005, Kim et al. 2006). In streams, DOC bioavailability is also affected by factors inherent in the biophysical conditions of the ecosystem such as hydrodynamics, retention times and streambed microbial activity (Kaplan \& Newbold 2003, Lyon \& Ziegler 2009, Ziegler et al. 2009). Current conceptual models of DOC biodegradability recognize a large variety of DOC compounds differing in concentration, molecule size and both kinetic and energetic properties (Amon \& Benner 1996, Kaplan \& Newbold 2003). Monomers are generally present at low concentrations, but they represent the smallest and most reactive carbon molecules, and-given relatively short spiralling lengths (i.e. downstream travel distances until uptake) - have been found theoretically to support most of the heterotrophic carbon demand in streams (Kaplan \& Newbold 2003, Berggren et al. 2010). In addition to this small pool of biologically labile molecules, a larger pool of more refractory molecules exists for which higher concentration compensates for slower rates of catabolism 
(Wetzel 1992). This pool provides a supplement to the heterotrophic ecosystem metabolism (Tranvik \& Höfle 1987, Moran \& Hodson 1994, Volk et al. 1997) and contributes to the longitudinal metabolic linkage of lotic ecosystems at larger spatial scales (Battin et al. 2003a, 2008, Kaplan \& Newbold 2003).

Biofilms are attached microbial communities with a spatially explicit organisation which offer ample opportunities for biotic interaction, such as co-metabolism and mutualism (Hansen et al. 2007). In streams, biofilms typically dominate microbial life and greatly influence carbon cycling (Lock et al. 1984, Battin et al. 2008). DOC uptake from the bulk liquid by biofilms is traditionally considered to be controlled by an external resistance to diffusion, imposed by the boundary layer, and by an internal resistance attributable to biofilm architectural features (Gantzer et al. 1988, Grady et al. 1999, De Beer \& Kühl 2001). The intrinsic bioavailability of a given DOC molecule supposedly influences the extent of exogenous controls on its metabolism, such as the boundary layer thickness. The uptake of highly bioavailable substances, such as monomeric glucose (Glc), is at least partially controlled by hydrodynamics (Kaplan \& Newbold 2003). In contrast, intrinsically less bioavailable molecules, such as arabinose (Ara), have a lower uptake rate within the biofilm; they build up lower concentration gradients across the boundary layer and should therefore be less influenced by flow conditions (Kaplan \& Newbold 2003). Wholeecosystem and mesocosm experiments generally support this perception showing an influence of flow velocity on the uptake of Glc but less so on the uptake of Ara (Battin et al. 2003a, Kaplan \& Newbold 2003). These studies are based on ecosystem-level observations and postulate a shift in susceptibility of a molecule to metabolism from its intrinsic bioavailability to mass transfer limiting diffusion into mature (and thick) biofilms.

The fine-scale biophysical processes driving this differential uptake of carbon monomers at ecosystem level remain largely elusive. Here, we postulate flowinduced architectural differentiation, gradients and diauxie (Monod 1942, Magasanik 1961) within biofilms as mechanisms underlying the differential uptake of Glc and Ara. We studied Glc and Ara uptake at the level of single cells, of entire biofilms and at the level of the flume microcosms harbouring the biofilms. Our study contributes to a better understanding of the role of external vs. internal mass transfer for resource uptake in microbial biofilms, and adds to our knowledge of the mechanisms of multiple substrate use by biofilms. Such mechanistic explanations of the microscale structure-function coupling of natural biofilms may improve our understanding of ecosystem-level DOC processing in streams.

\section{MATERIALS AND METHODS}

Experimental setup, sampling and statistical considerations. Biofilms were grown in laboratory microcosms from raw oligotrophic stream water (Piesting, Austria) under 3 different hydrodynamic treatments for a period of 74 to $81 \mathrm{~d}$. We performed 2 injection experiments with radioactively labelled ('hot') Glc and Ara at 2 different Glc:Ara ratios. The 2 experiments were carried through in separate microcosms and with fresh biofilm within $1 \mathrm{wk}$. The source communities for the 2 experiments were identical, and biofilm biomass parameters indicated a high level of similarity, but the biofilms used in these experiments differed slightly in age (74 vs. $81 \mathrm{~d})$.

The microcosms consisted of flumes made of acrylic glass (length $1.3 \mathrm{~m}$; width $2 \mathrm{~cm}$; height $2 \mathrm{~cm}$ ) and are described fully in Singer et al. (2006). Sterile unglazed ceramic coupons $(1 \times 2 \mathrm{~cm})$ served as a substratum for biofilm growth. The water flow was adjusted to yield a constant-flow environment with specific velocity, depth and open-channel Reynolds number. The dimensionless Reynolds number $\left(R e_{\mathrm{f}}\right)$ for open-channel flow was calculated as $\left(u L_{R}\right) / v$, where $u$ is current velocity, $v$ is kinematic viscosity, and $L_{\mathrm{R}}$ is the hydraulic radius calculated from the flume width $\left(L_{\mathrm{w}}\right)$ and water depth $\left(L_{\mathrm{h}}\right)$ according to $\left(L_{\mathrm{h}} L_{\mathrm{w}}\right) /\left(L_{\mathrm{w}}+2 L_{\mathrm{h}}\right)$. Water depth was $0.7 \mathrm{~cm}$ and constant for all microflumes. Three hydrodynamic treatments with laminar, intermediate and turbulent flows were achieved by adjusting the slope and flow rate in each flume individually (Table 1). The transition from laminar to turbulent flow was confirmed by rhodamine injections as described by Singer et al. (2006). The flow velocities bracketed those typically encountered in third order streams (Gordon et al. 2004). Flow rates were regularly checked and kept constant throughout biofilm growth and monomer uptake experiments. Water was recirculated within and among treatments to ensure homogeneity of the microbial inoculum and water chemistry, and ca. $75 \%$ of the entire water volume was renewed every third day except for the period between the 2 experiments. The stream water nutrient concentrations (average $\pm \mathrm{SD}$ ) were $21 \pm 5 \mu \mathrm{g} \mathrm{NH}-\mathrm{N} \mathrm{l}^{-1}$ and

Table 1. Reynolds numbers and flow velocities of the 3 flow treatments; the means and standard deviations are computed from replicate microcosms ( $\mathrm{n}=$ no. of microcosms) used for biofilm cultivation

\begin{tabular}{|lccc|}
\hline Flow treatment & $\mathrm{n}$ & Reynolds number & Velocity $\left(\mathrm{cm} \mathrm{s}^{-1}\right)$ \\
\hline Laminar & 16 & $262.1 \pm 13.5$ & $6.62 \pm 0.34$ \\
Transitional & 17 & $627.8 \pm 27.0$ & $15.87 \pm 0.68$ \\
Turbulent & 19 & $1544.8 \pm 22.9$ & $39.05 \pm 0.58$ \\
\hline
\end{tabular}


$779 \pm 138 \mu \mathrm{g} \mathrm{NO} \mathrm{NO}_{3}-\mathrm{N} \mathrm{l}^{-1}$; the soluble reactive phosphorus was usually below the detection limit $\left(<50 \mu \mathrm{g} \mathrm{l}^{-1}\right)$; conductivity was $435 \pm 6 \mu \mathrm{S} \mathrm{cm} \mathrm{cm}^{-1}$. Controlled light (mean photon flux density of $31.6 \mu \mathrm{mol} \mathrm{m} \mathrm{m}^{-2} \mathrm{~s}^{-1}$ during a $12 \mathrm{~h}$ light period per day) and temperature $\left(15^{\circ} \mathrm{C}\right)$ ensured constant environmental conditions. A pilot study using the same microcosms (Singer et al. 2006) rigorously assessed the variation of biofilm parameters at various experimental levels (i.e. variation within microcosms, among microcosms and among separate water reservoirs) relevant to this study. The pilot study identified good reproducibility at the level of replicate water reservoirs and experimental microcosms, and clearly assigned the highest variance component (ca. 90\%) to within-microcosm replication. In the present study, for biofilm growth we used replicate microcosms for each hydrodynamic treatment and one common water reservoir to assure equal inoculum for all treatments. To investigate monomer uptake, multiple coupons with mature biofilms were collected from replicate microcosms of the same hydrodynamic treatment (i.e. laminar, transitional, turbulent) and transplanted into 3 single microcosms, one for each hydrodynamic treatment, each with a minimised and separate water volume and with either radiolabelled Glc or Ara (resulting in a total of 6 microcosms for each experiment). Thus, variation for biomass originates from within and among microcosms seen from both a biofilm and a hydrodynamic point of view. Variation of uptake-related parameters stems from within and among microcosms regarding the used coupons with biofilm, but from within-microcosm only from a hydrodynamic point of view. Given the support from the pilot study and the fact that hydrodynamic treatments spanned almost an order of magnitude with very little and clearly non-overlapping variation (Table 1), we consider this as a valid approach to test our hypotheses.

We added tritiated Glc and Ara (Sigma Aldrich; specific activity: $20 \mathrm{Ci} \mathrm{mmol}^{-1}$, adjusted to 2-5 $\mathrm{Ci} \mathrm{mmol}^{-1}$ with cold Glc or Ara, respectively) to the microcosm to study monomer uptake by mature biofilms. In each microcosm used for uptake experiments, 4 coupons with biofilms were used as killed controls $(2.5 \%$ formaldehyde final concentration, $15 \mathrm{~min}$ ) to account for adsorption of $\mathrm{Glc}$ and Ara. One radiolabelled monomer (either Glc or Ara) was injected simultaneously with the complementary unlabelled monomer in each of 2 microcosms for each hydrodynamic treatment. In a first experiment (Expt 1), we used equal concentrations of Glc and Ara $\left(0.1 \mu \mathrm{mol} \mathrm{l^{-1 }}\right)$. To ensure successful labelling of cells by Ara given the expected low uptake rates compared to Glc, a second experiment (Expt 2) was performed with a reduced Glc concentration $\left(0.01 \mu \mathrm{mol} \mathrm{l^{-1 }}\right)$ yielding a Glc:Ara ratio of 1:10. Table 2 summarizes concentrations and activities for both experiments. Biofilm age was $74 \mathrm{~d}$ and $81 \mathrm{~d}$ for Expt 1 and Expt 2, respectively. Thus, variation between the 2 experiments originates from different Glc:Ara ratios and may also be influenced by different biofilm ages. After 125 min of incubation (recirculating the same water including the radiolabel), 10 ceramic coupons with biofilm were sampled from each microcosm, transferred into $2.5 \%$ formaldehyde and stored $\left(4^{\circ} \mathrm{C}\right)$ pending analysis. The control coupons were subject to the same treatment. Ten additional biofilm samples were preserved (4\% paraformaldehyde) and immediately embedded in Optimal Cutting Temperature (OCT) Compound (Tissue Tek) and frozen $\left(-80^{\circ} \mathrm{C}\right)$.

Microcosm and biofilm-level monomer uptake. Water samples $(2 \mathrm{ml})$ were collected repeatedly during the incubation period and radioassayed in $18 \mathrm{ml}$ of scintillation cocktail (Ultima Gold) on a 1600 TR Packard liquid scintillation counter. Microcosm-level removal of labelled monomers was computed from exponential fits of decreasing radioactivity in the water samples over time:

$$
A_{\text {norm }}=\mathrm{e}^{-u \cdot t}
$$

where $A_{\text {norm }}$ is the normalized activity $A(t) / A\left(t_{0}\right)$ of the water sample, $t$ is time and $u$ is the system-level uptake rate (units: $\min ^{-1}$ ). Exponential models were expressed in their linear transformation, and a 2-way analysis of covariance (ANCOVA) homogeneity-of-slopes-model was used to test for differences of removal rates among treatments (i.e. 3 microcosms with laminar, transitional, and turbulent treatments) and between monomer ratios (i.e. 2 experiments with differing ratios of Glc:Ara). Normal distribution was checked by Q-Q plots and Kolmogorov-Smirnov tests; variance homogeneity was assessed by the Levene test.
Table 2. Activities and concentrations of tritiated glucose (Glc) and arabinose (Ara). Concentrations were equal in all 3 flow treatments (see Table 1)

\begin{tabular}{|c|c|c|c|c|c|c|c|c|c|}
\hline \multirow{3}{*}{$\begin{array}{c}\text { Glc }^{\text {Mic }} \\
\text { activity } \\
\left(\mu \mathrm{Ci} \mathrm{ml^{-1 }}\right)\end{array}$} & \multicolumn{3}{|c|}{ icrocosm 1 (Glc uptake) } & \multirow{3}{*}{$\begin{array}{l}\overline{\text { Ara }} \\
\text { conc. } \\
\left(\mu \mathrm{mol} \mathrm{l}^{-1}\right)\end{array}$} & \multicolumn{5}{|c|}{ — Microcosm 2 (Ara uptake) } \\
\hline & \multicolumn{3}{|c|}{$\begin{array}{l}\text { Glc conc. } \\
\left(\mu \mathrm{mol} \mathrm{l}^{-1}\right)\end{array}$} & & \multirow{2}{*}{$\begin{array}{c}\text { Ara } \\
\text { activity } \\
\left(\mu \mathrm{Ci} \mathrm{ml} \mathrm{m}^{-1}\right)\end{array}$} & \multicolumn{3}{|c|}{$\begin{array}{l}\text { Ara conc. } \\
\left(\mu \mathrm{mol} \mathrm{l} \mathrm{l}^{-1}\right)\end{array}$} & \multirow{2}{*}{$\begin{array}{c}\text { Glc } \\
\text { conc. } \\
\left(\mu \mathrm{mol} \mathrm{l}^{-1}\right)\end{array}$} \\
\hline & Total & Hot & Cold & & & Total & Hot & Cold & \\
\hline \multicolumn{10}{|c|}{ Expt 1 (Glc:Ara monomer ratio = 1:1) } \\
\hline 0.5 & 0.1 & 0.025 & 0.075 & 0.1 & 0.5 & 0.1 & 0.025 & 0.075 & 0.1 \\
\hline \multicolumn{10}{|c|}{ Expt 2 (Glc:Ara monomer ratio = 1:10) } \\
\hline 0.2 & 0.01 & 0.01 & 0.0 & 0.1 & 0.5 & 0.1 & 0.025 & 0.075 & 0.01 \\
\hline
\end{tabular}


Biofilms were scraped off the coupons and the slurry transferred to sterile vials, thoroughly vortexed and then filtered onto $0.2 \mu \mathrm{m}$ membrane filters (Millipore) with 2 washing steps (2.5 $\mathrm{ml}$ ice-cold MilliQ water). Filters were transferred into scintillation vials with $18 \mathrm{ml}$ of scintillation cocktail and radio-assayed. Timeaverage cell-specific incorporation rates of Glc and Ara were calculated from the label detected in the biofilm samples and from average bacterial abundance determined on parallel samples, and from the incubation time. Since both radiolabel incorporation and bacterial abundance are subject to independent variation, cellspecific rates are a statistically non-testable quantity. We therefore computed bootstrap confidence intervals (Manly 2006) to allow robust comparisons of cell-specific incorporation rates and their Ara:Glc ratios among flow treatments and between experiments. Additionally, area-specific biofilm incorporation rates were used in 1-way analysis of variance (ANOVA) to test directly for effects among treatments (i.e. 3 microcosms with laminar, transitional, and turbulent treatments) separately for each experiment and carbohydrate. Data were log-transformed to meet assumptions for ANOVA.

Cryosectioning, staining, and microautoradiography. Biofilm samples from Expt 1 (Glc:Ara ratio = 1:1) were used to study incorporation of Glc, and samples from Expt 2 (Glc:Ara ratio = 1:10) were used to study incorporation of Ara. Cryosections $(6 \mu \mathrm{m})$ were produced from the OCT-embedded biofilm samples (along the $X Z$-plane) with a cryostat (Mikrom HM505E) and transferred onto poly-L-lysine-coated slides. Cryosections were dehydrated through graded ethanol solutions $(70,90$ and $100 \%$ ethanol, $3 \mathrm{~min}$ each) and air-dried. Cells in the cryosections were stained (10 min) with $10 \mu \mathrm{l}$ of $5 \mu \mathrm{mol} \mathrm{l} \mathrm{l}^{-1}$ SYTO $^{\circledR} 13$ solution (Invitrogen). To visualize uptake of radiolabelled monomers at cell level, we performed microautoradiography (MAR) (Andreasen \& Nielsen 1997, Lee et al. 1999). Slides were dipped (5 s) into an autoradiographic emulsion EM-1 (Amersham), which is particularly sensitive and therefore suitable for low-energy emitters such as $\left[{ }^{3} \mathrm{H}\right]$-labelled compounds. The emulsion was solidified by placing the slides horizontally on an iced plastic plate for $10 \mathrm{~min}$ and subsequently dried for $2 \mathrm{~h}$ at ambient temperature. Exposure times at $4^{\circ} \mathrm{C}$ were $7 \mathrm{~d}$ for $\left[{ }^{3} \mathrm{H}\right]$-Glc-labelled samples and $30 \mathrm{~d}$ for $\left[{ }^{3} \mathrm{H}\right]$-Ara-labelled samples, respectively. Slides were developed (Kodak D19, 3 min), transferred to a stop solution (deionized water, 1 min), fixed with $30 \%$ sodium thiosulphate and finally washed in deionized water for $2 \mathrm{~min}$. Confocal laser scanning microscopy (CLSM, LSM 510 Zeiss) was used to record the spatial distribution of SYTO13-labelled cells in the biofilm (XZ-axes). To determine the spatial distribution of Glc- vs. Ara-labelled cells in the biofilm, silver grains in the autoradiographic film were recorded using the transmission mode of the microscope in bright-field illumination.

MAR image processing and data analysis. CLSM images (in .tif file format) were processed with ImageJ (version 1.34) and Adobe Photoshop Elements (version 4.0). Regions with labelled cells were randomly selected and their height and width determined. Along the $Z$-axis, each region was divided into 5 relative depth layers of equal height, and relative MAR signals, rMAR, determined in each depth layer as:

$$
\mathrm{rMAR}=\frac{\mathrm{aMAR}}{\sum_{i=1}^{5} \mathrm{aMAR}_{i}}
$$

where aMAR is the (absolute) surface area of silver grains in one of the 5 depth layers and the index $i$ numbers the depth layers.

To investigate depth gradients of Glc uptake in biofilms, we fitted a simple exponential model as a first approximation to the nonlinear uptake profiles:

$$
\frac{\mathrm{aMAR}}{\mathrm{AREA}}=a \cdot \mathrm{e}^{-b \cdot d_{\mathrm{PATI}}}
$$

which considers the area-specific absolute MAR signal (aMAR/AREA with 'AREA' being the total area of the depth layer; units: \%) as a function of supply at the biofilm surface (constant a), internal biofilm diffusion resistance (exponent $b$ ) and travel distance $\left(d_{\mathrm{PATH}}\right.$, distance from biofilm surface to centre of depth layer). As Glc concentration (and total amounts) in the bulk liquid were equal among flow treatments, the constant $a$ varies mainly as a function of Glc transfer efficiency through the diffusive boundary layer. Models were fitted in linearized form after $\ln (x+0.003)$ transformation to allow inclusion of zeros (the added constant 0.003 being the minimum aMAR/AREA found). Individual fits were computed for each randomly selected region and fitted parameters were compared among flow treatments (i.e. the 3 microcosms with laminar, transitional and turbulent treatments) using 1-way ANOVA.

Bacterial abundance and chlorophyll a. Bacterial abundance was determined on coupons treated with $0.1 \mathrm{mmol} \mathrm{l}^{-1}$ tetrasodium pyrophosphate $(1 \mathrm{~h}$, rotary shaker) and subsequently sonicated (180 s, 40 W output, Branson Sonifier 250) and thoroughly vortexed to detach and disaggregate bacterial cells (Velji \& Albright 1986). An aliquot of the suspension was stained with 4', 6-diamidino-2-phenylindole, (DAPI, Invitrogen, $1 \mathrm{mg} \mathrm{ml}^{-1}$ final concentration) and filtered onto a $0.2 \mu \mathrm{m}$ isopore membrane black polycarbonate filter (Millipore). Bacteria were enumerated in 30 randomly selected fields to account for 300 to 500 cells by using epifluorescence microscopy (Nikon E800). To determine 
chlorophyll a (chl a), coupons were collected in parallel and chl a was extracted with p.a. grade acetone in the dark $\left(12 \mathrm{~h}, 4^{\circ} \mathrm{C}\right)$. Samples were thoroughly vortexed, the supernatant filtered (GF/F Whatman) and assayed fluorometrically (RF-1501 Shimadzu, EX435/ EM675) using spinach (Sigma-Aldrich) as standard. Two-way ANOVA was employed to test for effects of flow treatments and experiment (i.e. biofilms of slightly different age were used for the 2 experiments with differing ratios of Glc:Ara) on bacterial abundance and chl a with assumptions for ANOVA checked as above. Data were log-transformed when necessary to meet assumptions. For each hydrodynamic treatment and both experiments, replicate coupons for both bacterial abundance and chl a originated from independent replicate microcosms used for biofilm cultivation.

\section{RESULTS}

\section{Bacterial abundance and chlorophyll a}

Mean bacterial abundance ranged from $7.17 \times 10^{7}$ to $9.89 \times 10^{7}$ cells $\mathrm{cm}^{-2}$ and average chl a concentrations ranged from 5.02 to $6.28 \mu \mathrm{g} \mathrm{cm}^{-2}$. A 2-way ANOVA with the factors flow treatment and experiment (i.e. 2 different biofilm ages used for the 2 experiments with differing Glc:Ara ratios) indicated a significant effect of flow treatment on log-transformed chl a $\left(F_{2,66}=11.4\right.$, $\mathrm{p}<0.001)$; chl a was higher in the laminar treatment compared to the other 2 flow treatments (Tukey HSD: $\mathrm{p}<0.01)$. There was no significant effect of experiment $\left(F_{1,66}=0.87, \mathrm{p}=0.36\right)$ and no significant interaction $\left(F_{2,66}=0.08, \mathrm{p}=0.92\right)$. Regarding bacterial abundance, there was no significant effect of flow treatment $\left(F_{2,38}=\right.$ $2.58, \mathrm{p}=0.09$ ) and a small difference between experiments $\left(F_{1,38}=4.44, \mathrm{p}<0.05\right)$ with slightly higher bacterial abundances during the second experiment with Glc:Ara $=1: 10$. These results are in agreement with Besemer et al. (2007) who analyzed bacterial abundance and chl a from the same experimental setup over the whole biofilm cultivation period of $81 \mathrm{~d}$ and reported similar values and high similarity among flow treatments for mature biofilms.

\section{Patterns of monomer use at microcosm and biofilm level}

System-level removal rates of Glc followed a clear trend of increasing uptake rates from the laminar to the turbulent microcosms in both experiments. The turbulent microcosm had significantly higher removal rates than did the laminar microcosm, or both the laminar and transitional microcosms, during Expt 1 and Expt 2, respectively (Table 3). System-level uptake rates of Ara

Table 3. Uptake rates of glucose (Glc) and arabinose (Ara) at the level of experimental microcosms. Model coefficients \pm SE are given as the slopes of linearized exponential models (units: $\min ^{-1}$ ) with sample size $\mathrm{n}$, and $\mathrm{r}^{2}$ and $\mathrm{p}$ of model. Reported results of ANCOVA with $\ln$ (normalized activities, $A_{\text {norm}}$ ) as dependent variable, time as covariate, and the factor microcosm (identical to flow treatment) show differences of uptake rates (slope-dependent variable vs. covariate) between treatments. The ANCOVA approach uses the interaction term of the factor with the covariate to test for homogeneity of slopes (i.e. uptake rates)

\begin{tabular}{|c|c|c|c|c|c|c|c|c|}
\hline \multirow[t]{2}{*}{ Flow treatment } & \multicolumn{4}{|c|}{ Glc uptake } & \multicolumn{4}{|c|}{$\longrightarrow$ Ara uptake } \\
\hline & Rate $\left(\times 10^{-4} \min ^{-1}\right)$ & $\mathrm{n}$ & $\mathrm{r}^{2}$ & $\mathrm{p}$ & Rate $\left(\times 10^{-4} \min ^{-1}\right)$ & $\mathrm{n}$ & $\mathrm{r}^{2}$ & $\mathrm{p}$ \\
\hline \multicolumn{9}{|c|}{ Expt 1 (Glc:Ara monomer ratio = 1:1) } \\
\hline Laminar microcosm & $8.1 \pm 0.4$ & 7 & 0.99 & $<0.001$ & $1.1 \pm 0.4$ & 7 & 0.57 & $<0.05$ \\
\hline Transitional microcosm & $13.0 \pm 0.9$ & 5 & 0.98 & $<0.001$ & $0.4 \pm 0.2$ & 5 & 0.55 & 0.094 \\
\hline Turbulent microcosm & $21.3 \pm 1.6$ & 7 & 0.97 & $<0.001$ & $0.6 \pm 0.3$ & 7 & 0.45 & 0.070 \\
\hline \multicolumn{9}{|l|}{ ANCOVA results } \\
\hline Factor & $\mathrm{df}$ & $F$ & $\mathrm{p}$ & & $\mathrm{df}$ & $F$ & $\mathrm{p}$ & \\
\hline Covariate time & 1,13 & 138.5 & $<0.001$ & & 1,13 & 0.1 & 0.74 & \\
\hline Microcosm & 2,13 & 1.2 & 0.32 & & 2,13 & 0.4 & 0.69 & \\
\hline Microcosm $\times$ Time & 2,13 & 8.4 & $<0.01$ & & 2,13 & 0.2 & 0.86 & \\
\hline \multicolumn{9}{|c|}{ Expt 2 (Glc:Ara monomer ratio = 1:10) } \\
\hline Laminar microcosm & $15.9 \pm 1.4$ & 7 & 0.96 & $<0.001$ & $2.7 \pm 0.7$ & 7 & 0.73 & $<0.01$ \\
\hline Transitional microcosm & $14.4 \pm 1.5$ & 7 & 0.94 & $<0.001$ & $1.2 \pm 1.3$ & 7 & 0.12 & 0.40 \\
\hline Turbulent microcosm & $31.2 \pm 3.5$ & 7 & 0.93 & $<0.001$ & $1.9 \pm 1.3$ & 6 & 0.28 & 0.22 \\
\hline \multicolumn{9}{|l|}{ ANCOVA results } \\
\hline Factor & df & $F$ & $\mathrm{p}$ & & df & $F$ & $\mathrm{p}$ & \\
\hline Covariate time & 1,13 & 56.1 & $<0.001$ & & 1,13 & 0.6 & 0.46 & \\
\hline Microcosm & 2,13 & 0.4 & 0.68 & & 2,13 & 0.2 & 0.81 & \\
\hline Microcosm $\times$ Time & 2,13 & 3.4 & 0.06 & & 2,13 & 0.0 & 0.99 & \\
\hline
\end{tabular}


were statistically indistinguishable among microcosms and generally 6 to 35 times lower than those of Glc. However, Ara uptake rates were generally higher during Expt 2, with a Glc:Ara ratio of 1:10 (Table 3). Biofilm-level incorporation rates were consistent with these results, with clear effects of the flow environment on Glc-incorporation during both experiments (Table 4, Fig. 1a). Area-specific Glc incorporation increased significantly from laminar to transitional, and again from transitional to turbulent flow, during Expt 1, and from laminar and transitional to turbulent flow during Expt 2 (no difference between laminar and transitional). Glc incorporation differed markedly between experiments, with roughly 10 times higher uptake at the 10 times higher Glc-supply during Expt 1 with a Glc:Ara ratio of 1:1 (Table 4, Fig. 1a). In contrast to the more ambiguous water column results for Ara, the area-specific incorporation of Ara into the biofilm exhibited a clearly decreasing trend from laminar to transitional and turbulent flow conditions. In Expt 1, a significant decrease from the laminar and transitional microcosms to the turbulent microcosm could be observed, while the laminar microcosm proved significantly higher compared to the other two in Expt 2 (Table 4). Cell-specific incorporation rates of Ara were indistinguishable among microcosms during Expt 1, but followed a decreasing trend with increasing flow velocity during Expt 2 (Fig. 1b). The differential uptake patterns of Glc and Ara finally found their integrated expression in clearly decreasing trends of Ara:Glc ratios of both system-level uptake and cell-specific incorporation rates with increasing flow velocity (Fig. 1c,d).

\section{Cell-level uptake of monomers}

Images resulting from MAR were subject to visual interpretation and digital image analysis in order to quantify and model Glc and Ara uptake over biofilm depth. Visual inspection of MAR cryosections (Figs. 2 \& 3) revealed that cell-level uptake of Glc was predominantly located in the biofilm canopy in all flow treatments, whereas Ara uptake was either distributed over the entire biofilm depth in the laminar and transitional flow treatments, or concentrated in basal biofilm layers in the turbulent flow treatment. Both Glc and Ara uptake frequently clustered around voids and protuberances (e.g. Fig. 2b); floating streamers showed no Ara uptake at all (Fig. 3f).

Digital image analysis allowed the differential quantification of Glc and Ara uptake over biofilm depth and made general patterns of uptake apparent (Fig. 4). In thin biofilms $(<50 \mu \mathrm{m})$, Glc uptake was more uniformly distributed over biofilm depth. However, with increasing biofilm thickness, Glc uptake became increasingly allocated to the biofilm canopy and decreased towards the base of the biofilm. While this trend was observed in microcosms of all flow treatments, it was particularly apparent in turbulent flow conditions. We found significant correlations of relative MAR signal intensities (rMAR) of Glc with biofilm depth in all cases except thin biofilms $(<50 \mu \mathrm{m})$ in the microcosm with laminar flow treatment. Spearman correlation coefficients indicated a stronger association of rMAR of Glc with biofilm depth in thicker biofilms and progressing from laminar to transitional and turbulent flow conditions

Table 4. Biofilm-level monomer incorporation rates. Area-specific average incorporation rates $\left(\mathrm{pmol} \mathrm{h}^{-1} \mathrm{~cm}^{-2}\right)$ and cell-specific average incorporation rates $\left(10^{-8} \mathrm{pmol} \mathrm{h}^{-1} \mathrm{cell}^{-1}\right)$ of glucose (Glc) and arabinose (Ara) for all microcosms and both experiments. Values presented are arithmetic means $\pm 95 \%$ confidence intervals. ANOVA results state differences of (log-transformed) areaspecific average incorporation rates between microcosms (identical to flow treatments). Superscript letters indicate results of Tukey HSD post hoc tests following significant treatment effects

\begin{tabular}{|c|c|c|c|c|c|c|}
\hline Flow treatment & \multicolumn{3}{|c|}{$\begin{array}{l}\text { Area rate } \\
\text { Glc uptake } \\
\text { Cell rate }\end{array}$} & \multicolumn{3}{|c|}{$\underset{\text { Area rate }}{\text { Ara uptake }}$ Cell rate } \\
\hline \multicolumn{7}{|c|}{ Expt 1 (Glc:Ara monomer ratio = 1:1) } \\
\hline Laminar microcosm & $9.83 \pm 1.09^{\mathrm{a}}$ & 10.2 & & $0.53 \pm 0.05^{\mathrm{a}}$ & 0.55 & \\
\hline Transitional microcosm & $18.57 \pm 2.60^{\mathrm{b}}$ & 25.9 & & $0.57 \pm 0.14^{\mathrm{a}}$ & 0.79 & \\
\hline Turbulent microcosm & $30.06 \pm 4.82^{\mathrm{c}}$ & 42.03 & & $0.35 \pm 0.09^{b}$ & 0.5 & \\
\hline \multicolumn{7}{|l|}{ ANOVA results } \\
\hline Factor & df & $F$ & $\mathrm{p}$ & $\mathrm{df}$ & $F$ & $\mathrm{p}$ \\
\hline Microcosm & 2,26 & 70.9 & $<0.001$ & 2,26 & 7.4 & $<0.01$ \\
\hline \multicolumn{7}{|c|}{ Expt 2 (Glc:Ara monomer ratio $=1: 10)$} \\
\hline Laminar microcosm & $1.95 \pm 0.37^{\mathrm{a}}$ & 1.97 & & $1.01 \pm 0.13^{\mathrm{a}}$ & 1.02 & \\
\hline Transitional microcosm & $1.88 \pm 0.49^{\mathrm{a}}$ & 2.17 & & $0.70 \pm 0.19^{b}$ & 0.8 & \\
\hline Turbulent microcosm & $3.50 \pm 0.69^{b}$ & 3.64 & & $0.51 \pm 0.04^{b}$ & 0.53 & \\
\hline \multicolumn{7}{|l|}{ ANOVA results } \\
\hline Factor & $\mathrm{df}$ & $F$ & $\mathrm{p}$ & $\mathrm{df}$ & $F$ & $\mathrm{p}$ \\
\hline Microcosm & 2,27 & 10.7 & $<0.001$ & 2,27 & 20.5 & $<0.001$ \\
\hline
\end{tabular}



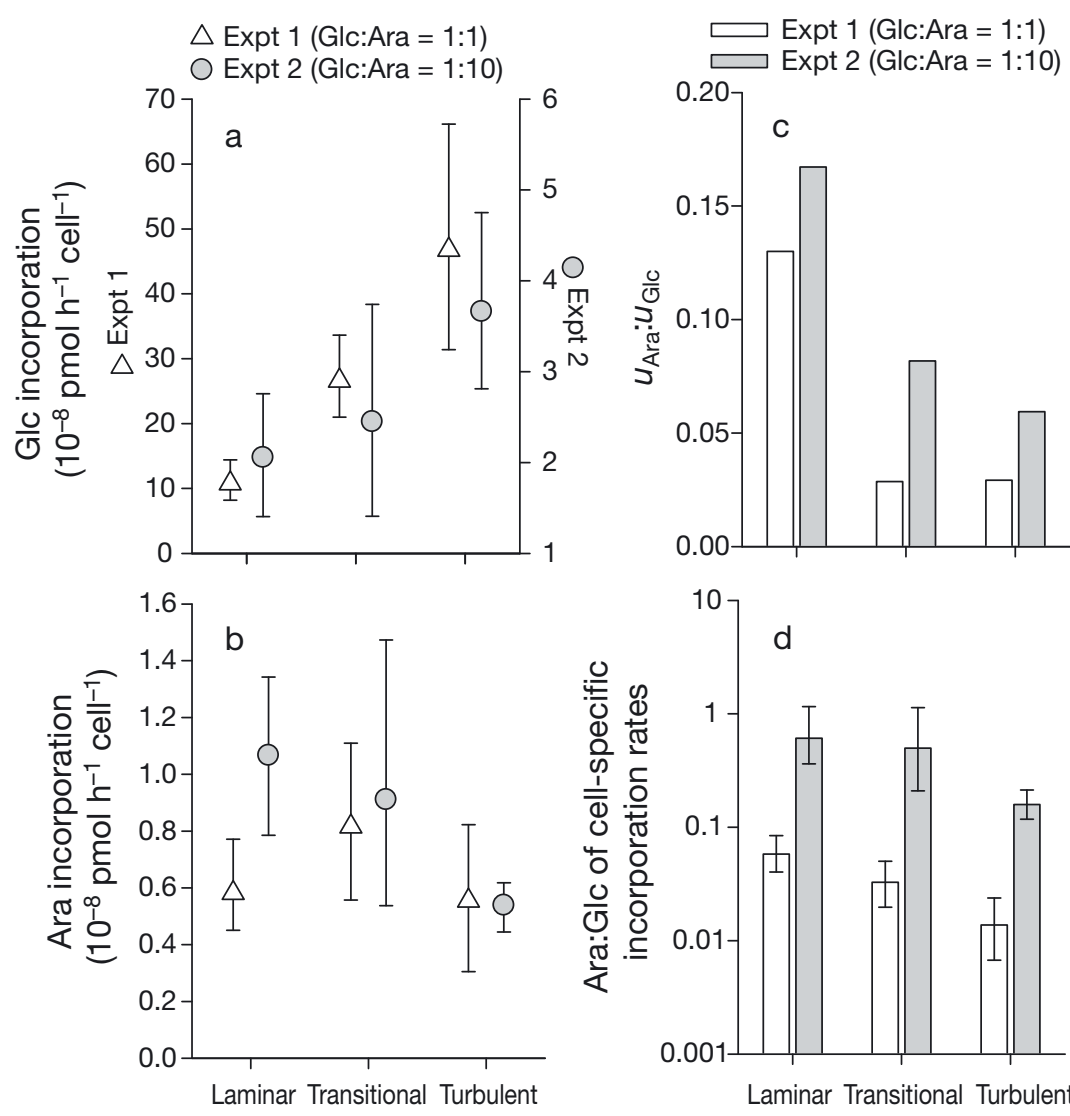

10

d

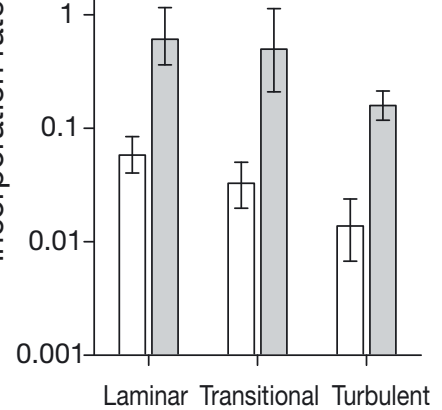

Flow treatment (microcosm)

Fig. 1. Mean cell-specific (a) Glc and (b) Ara incorporation rates. Ratio Ara:Glc between (c) system level removal rates $(u)$ and (d) cell-specific incorporation rates. Error bars in (a), (b) and (d) represent 95\% confidence intervals computed by bootstrapping and Bonferroni-corrected for multiple comparisons. Non-overlapping error bars indicate significant differences at an experiment-wise error rate of 0.05 . See Table 4 and Fig. 1 for sample sizes of associated variables

(Fig. 4). Relatively even Ara uptake across biofilm depth was generally observed across all treatments and biofilms varying in thickness. While no explicit trend was found in the laminar microcosm, trends of increasing Ara uptake with increasing biofilm depth were found in thicker biofilms $(>50 \mu \mathrm{m})$ under transitional and turbulent flow (Fig. 4). We found a significant negative correlation of Glc and Ara uptake over biofilm depth and thickness (Fig. 5). The correlation pattern is strongly supported by thicker biofilms which produce the most extreme values for Glc and Ara uptake in the various biofilm depth layers (Fig. 5a), and by the turbulent flow treatment which produced the most obvious vertical stratification patterns for both substrates (Fig. 5b).

Models fitted to depth gradients of Glc uptake (Fig. 6) point to external and internal limitations to mass transfer controlling Glc consumption. Both model coefficients followed conspicuous trends across all 3 flow treatments (Figs. $6 \&$ 7). The constant a (indicating supply at the biofilm surface and external mass transfer limitation) increased significantly from the laminar to the turbulent microcosm (1-way ANOVA with linear model coefficient $\ln (a)$ as dependent: $F_{2,117}=4.17$, $\mathrm{p}<0.05$ ). The exponent $b$ (indicating internal mass transfer limitation) also follows a clearly increasing, but insignificant trend across the flow treatments (1-way ANOVA: $F_{2,117}=2.32, \mathrm{p}=$ $0.10)$.

\section{DISCUSSION}

\section{Carbon catabolite repression leads to metabolic stratification}

Combining several spatial scales and techniques, our study demonstrates the specific distribution of monomer uptake in biofilms and its relation to flow and induced biofilm architecture. Our results thus provide mechanistic understanding and supportive evidence for the observed ecosystem-level observations of monomer dynamics in streams (Kaplan \& Newbold 2003). Furthermore, our results suggest, for the first time, carbon catabolite repression, i.e. the inhibited use of secondary substrates in the presence of a preferred substrate (Magasanik 1961, Görke \& Stulke 2008), as a complementary mechanism underlying monomer uptake in stream biofilms. The classic example of selective substrate use is the glucose-lactose diauxie in Escherichia coli first described by Monod (1942). Diauxic growth is characterized by the sequential use of Glc and lactose from a mixed substrate environment. In batch culture diauxic growth is typically accompanied by a second lag phase in the growth curve at the time of switching to the less preferred substrate (Görke \& Stulke 2008, Madigan et al. 2008). Monod (1942) has shown the same phenomenon to occur specifically for Glc and Ara. We argue that in biofilms attached to a surface, the unidirectional and downward flux of substrates from the water to the biofilm - along with preferential use (and depletion) of primary substrates (i.e. suppression of secondary substrate use) within the biofilm - can lead to spatially segregated substrate use and hence to 'metabolically stratified' biofilms. This is, in fact, supported by the MAR findings documenting vertical gradients of Glc 

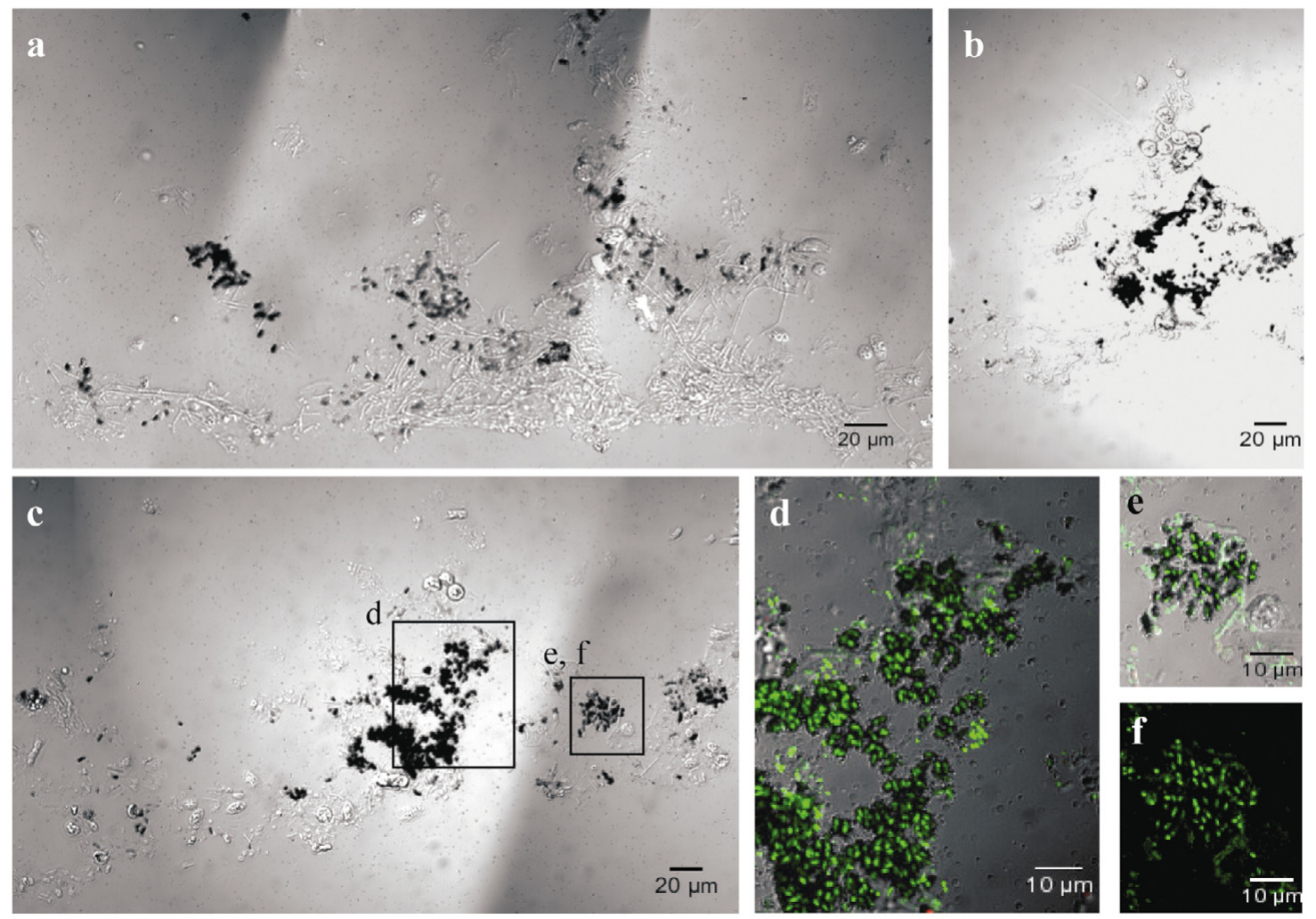

Fig. 2. Confocal images on cryosections showing (a) uptake of Glc in canopy but not basal layers of biofilm in laminar flow microcosm, (b) enhanced uptake around a void, presumably a channel cross-section, and (c-f) microautoradiographic signals of Glcuptake and corresponding deoxyribonucleic acid-stained bacteria (SYTO 13) in laminar flow microcosm. Patterns of vertical stratification of Glc uptake were similar and often stronger in transitional and turbulent flow treatments

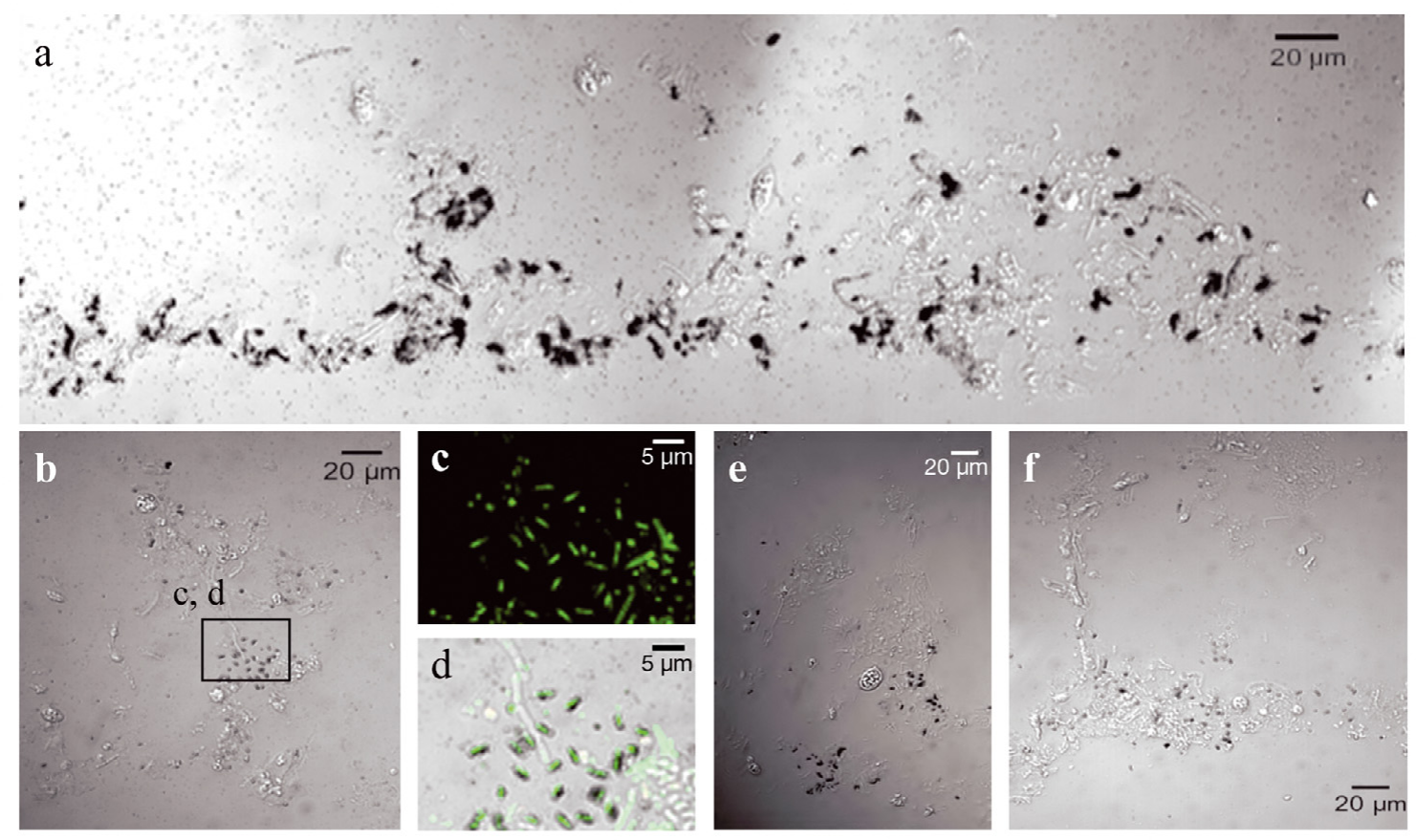

Fig. 3. Confocal images on cryosections showing (a) uptake of Ara uniformly distributed across biofilm depth in laminar flow microcosm, (b-d) microautoradiographic signals of Ara-uptake and corresponding stained bacteria (SYTO 13) in turbulent flow microcosm,

(e) Ara-uptake limited to basal biofilm layers in turbulent flow microcosm, and (f) biofilm streamer in turbulent flow microcosm 

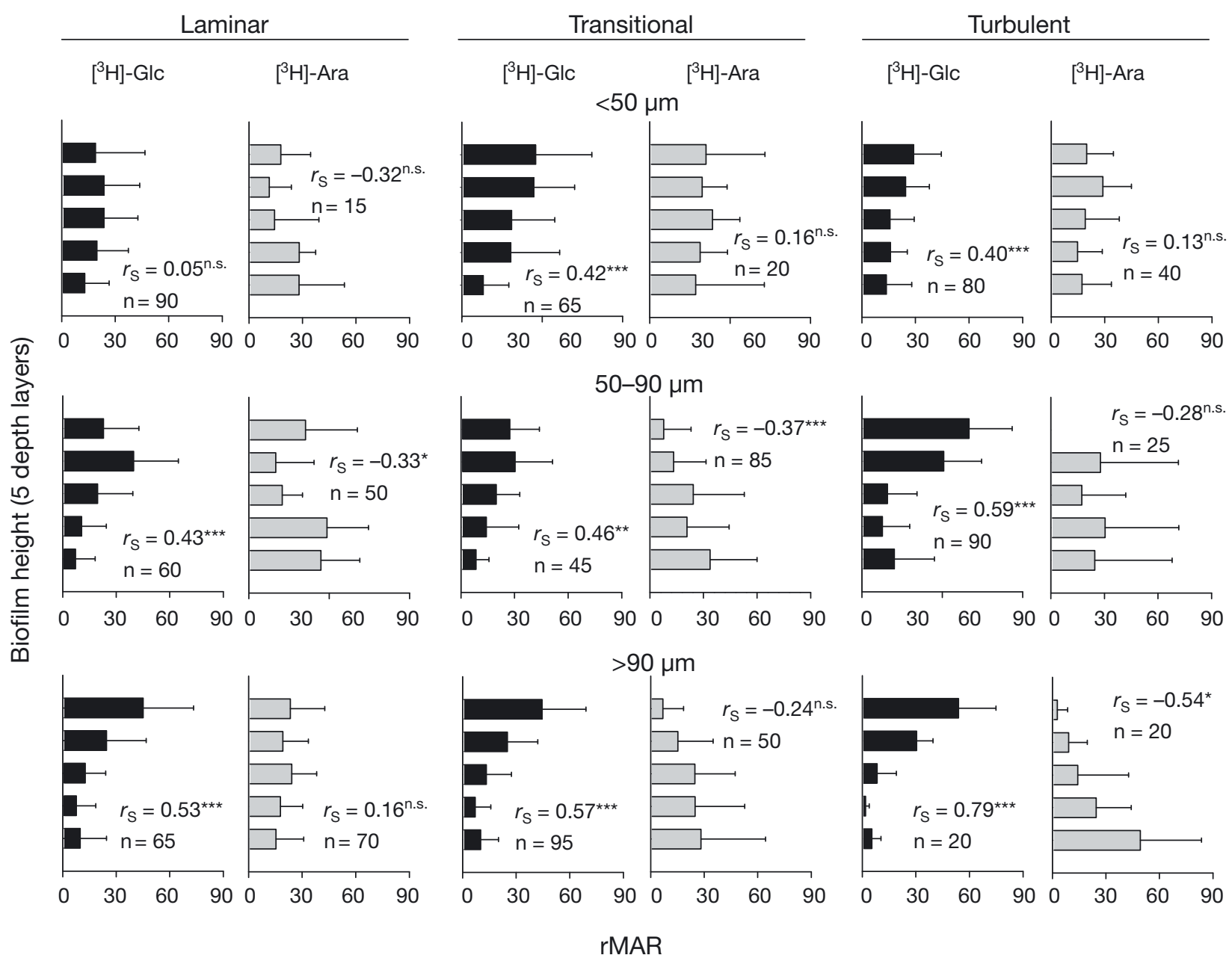

Fig. 4. Depth gradients of relative microautoradiograph (rMAR) signals of Glc and Ara uptake over 5 depth layers in biofilms of various total thickness $(<50 \mu \mathrm{m}, 50-90 \mu \mathrm{m},>90 \mu \mathrm{m})$ in the laminar, transitional and turbulent flow microcosms. Bars represent mean rMAR signals \pm SD (see 'Materials and methods'), biofilm height is given on the $y$-axis (uppermost of 5 depth layers is closest to biofilm surface). Numbers given are Spearman's rank correlation coefficient $r_{\mathrm{S}}$ with significance values indicated by asterisks $\left({ }^{* * *} \mathrm{p}<0.001,{ }^{* *} \mathrm{p}<0.01,{ }^{*} \mathrm{p}<0.05\right.$; n.s.: not significant) and corresponding sample size $\mathrm{n}$ (total number of depth layers)

and Ara uptake in biofilms of various thickness and under different flow regimes (Figs. 4 \& 5). Glc uptake was highest near the biofilm surface, whereas Ara uptake was elevated near the biofilm base - a pattern that was most pronounced in the thicker $(>90 \mu \mathrm{m})$ biofilms in turbulent flow.

\section{External and internal mass transfer influence within-biofilm stratification}

The relationship between Glc MAR signals and biofilm depth clearly changed from laminar to transitional and to turbulent flow (Fig. 6). This shift suggests, at least in part, a control of flow on external mass transfer with enhanced Glc supply at the biofilm surface in faster flow, presumably a consequence of a thinner diffusional boundary layer. Increased within-biofilm resistance to diffusion under turbulent flow (due to biofilm density) and subsequently reduced loss of Glc to deeper biofilm layers may further strengthen the observed vertical gradient of Glc-uptake within biofilms. However, Glc uptake at the cell, biofilm and at the microcosm level increased with flow, which suggests at least partial control of boundary layer related processes on the establishment of the vertical gradients of Glc uptake in biofilms.

The evidence for internal mass transfer resistance increasing from laminar to turbulent flow is interesting in itself. Increased biofilm density at higher flow velocities (Characklis \& Marshall 1990, Beyenal \& Lewandowski 2002) was interpreted as a response to high shear stress and drag forces, while, at the same time, it decreases effective diffusivity and thus limits within- 
biofilm mass transport (Beyenal \& Lewandowski 2002). Indeed, such a trade-off between mechanical stability and optimized substrate delivery within biofilms may explain Ara uptake despite good Glc supply. Low diffusion may generate patches of low Glc supply, and thus Ara demand, even at optimal external Glc supply (i.e. high concentration in the bulk water and low boundary layer dimension). At the same time, restricted uptake of Glc in the biofilm canopy may suppress the uptake of Ara facilitating its diffusion into the

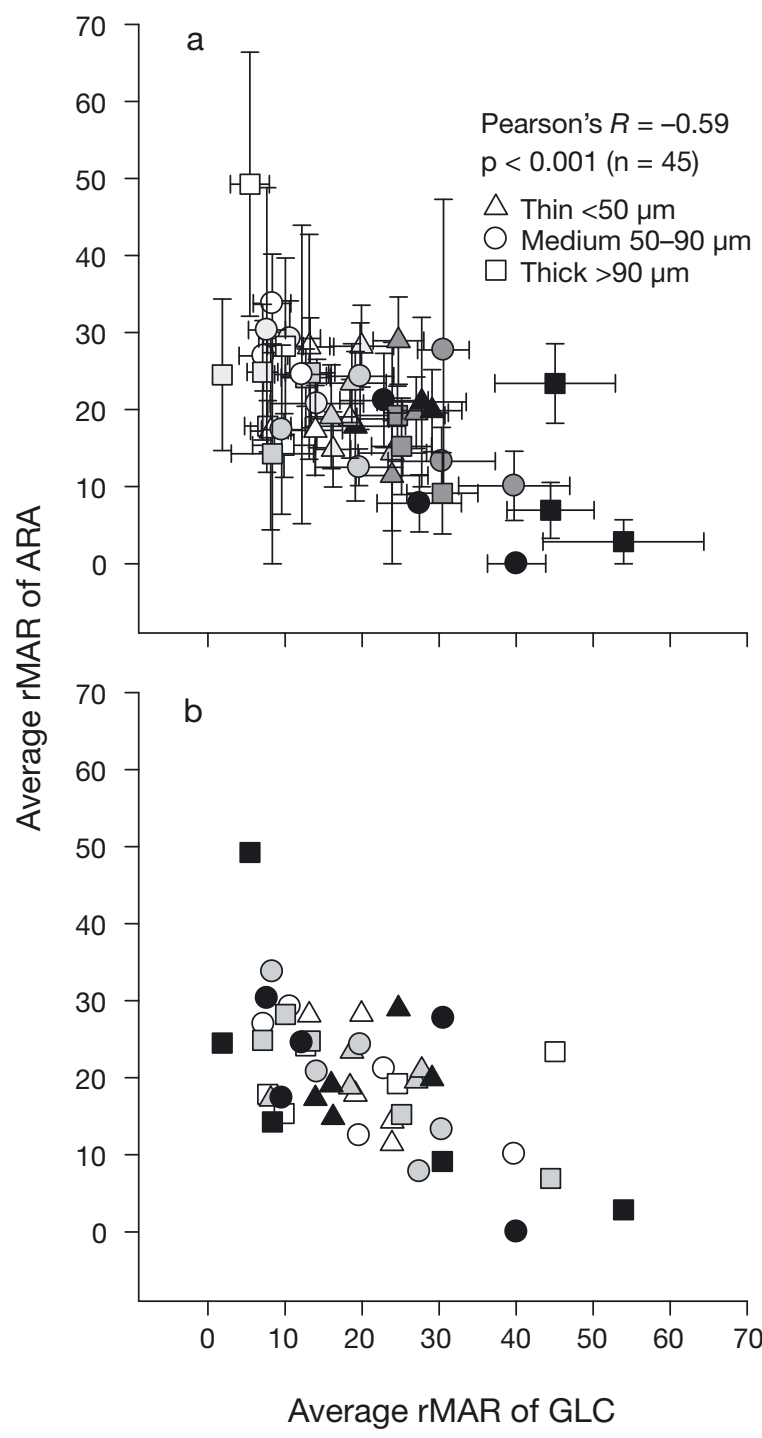

Fig. 5. Relationship between relative microautoradiograph (rMAR) signals of Glc and Ara uptake for (a) biofilm depth layer and (b) flow environment. In (a), lighter shades refer to deeper biofilm layers and darker shades to layers closer to the canopy. In (b), the intensity of the shade increases from laminar to turbulent flow. Given are mean rMAR signals (see 'Materials and methods') for 1 of 5 depth layers in 1 of 3 biofilm thickness classes across all flow environments $(\mathrm{n}=45)$; error bars in (a) represent standard errors

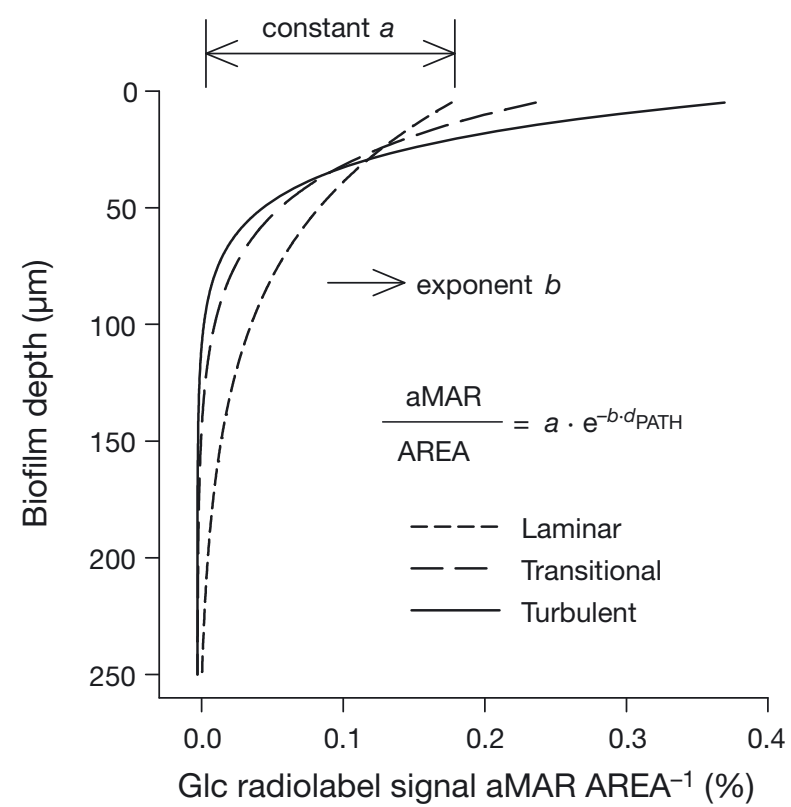

Fig. 6. Average models for Glc uptake changing with biofilm depth. Curves are calculated and drawn using average model constant a (i.e. supply at biofilm surface and effects limiting external mass transfer) and exponent $b$ (i.e. internal biofilm diffusion resistance) for the 3 microcosms with laminar, transitional, and turbulent flow

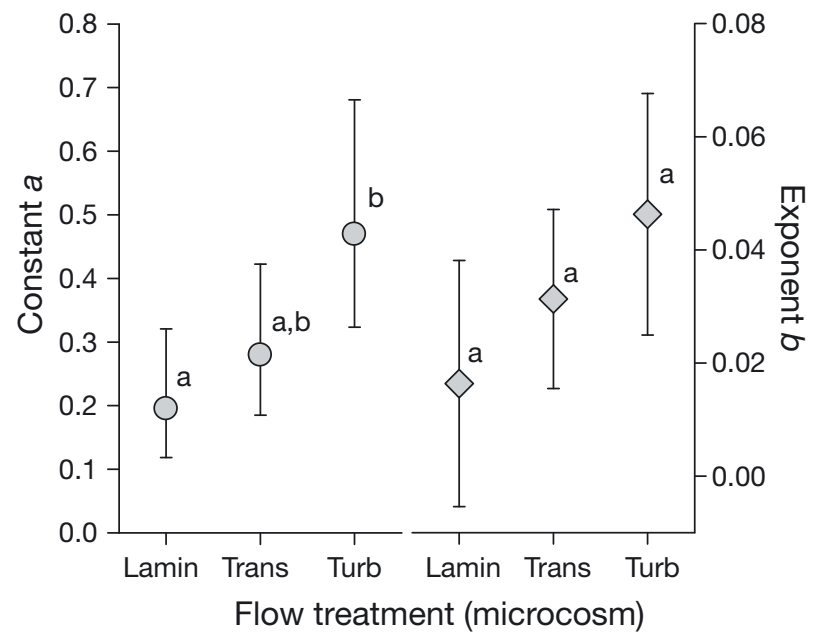

Fig. 7. Coefficients for models of Glc uptake related to biofilm depth. Effects of flow environment (lamin: laminar; trans: transitional; turb: turbulent) on coefficients of models describing Glc incorporation trends with biofilm depth: constant $a$ describes supply at biofilm surface and effects of limiting external mass transfer, and exponent $b$ describes internal biofilm diffusion resistance. Given are mean coefficients and $95 \%$ confidence intervals, sample size $\mathrm{n}=38-42$ for each treatment. Lower-case letters indicate significant differences between treatments as identified by Tukey HSD post hoc tests following a significant treatment effect in a 1-way ANOVA run for linear model fitted coefficients (see 'Materials and methods') 
deeper layers of the biofilm. Local Ara uptake in the deeper biofilm layers is apparent from our MAR results from the turbulent flow treatment. We have not determined biofilm density in this study; however, others have shown the compacting effect of flow velocity on stream biofilms (Battin et al. 2003b). Therefore, we assume that biofilms from laminar flow were less dense and that metabolic stratification is less pronounced. Ara uptake would therefore result from reduced external Glc supply in these biofilms.

In this context, it is interesting to note that coefficients from models fitted to describe depth gradients of Glc uptake from MAR signals exhibited trends of progressively lower variation from laminar to transitional and turbulent flow (standard deviations are 0.07, 0.05 and 0.065 for the exponent $b$, and 1.60, 1.29 and 1.13 for $\ln (a)$ for laminar, transitional, and turbulent microcosms, respectively). Highly variable depth gradients mean less clear stratification and more important localized substrate supply anywhere along the depth axis. This can be interpreted as an indication for advective transport through channels and voids as visible in Fig. 2b. Advective transport has in fact been shown to enhance solute transport into and within biofilms with higher structural heterogeneity (De Beer et al. 1996, Picioreanu et al. 2000, De Beer \& Kühl 2001). In slow flow, advective transport may enable biofilms to maintain limited access to external carbon sources. Only at very slow flow velocities $\left(<1 \mathrm{~cm} \mathrm{~s}^{-1}\right)$, the beneficial effect of advective transport has been shown to disappear as even heterogeneous biofilms may behave as a planar slab where diffusion dominates (De Beer \& Kühl 2001). Our experiments were performed using flow velocities well above this threshold.

Ara uptake as a balanced result of external and internal controls on mass transfer to and within biofilms offers an explanation for the cell-specific Ara uptake patterns at high and low Glc supply (Fig. 1b). While the external limitation decreased from the laminar to the turbulent treatment, internal limitation seemingly increased across these same flow treatments. The depth gradient of Ara uptake with flow velocity depends on both limitation steps and is mediated by the supply of Glc. At high Glc mass transfer to the biofilm (i.e. high concentration and high flow velocity), internal effects are important and would explain the still considerable Ara uptake in the turbulent treatment. Under such conditions, the observed gradients of Ara uptake with flow velocity would depend on the balance between external and internal limitations to mass transfer, and would be weak or virtually absent. Theoretically, at very high Glc supply, purely internal effects could generate a gradient of Ara uptake that increases from laminar to turbulent flow. At lower Glc supply to the biofilm (i.e. low concentra- tion and/or low flow velocities), external limitation would increase and would generate a pronounced decreasing gradient of Ara uptake from laminar to turbulent flow.

\section{Patterns of uptake from the cell to the biofilm and microcosm level}

At the level of the entire biofilm, the overwhelming effect of external mass transfer limitation became obvious with Glc uptake rates differing almost 5-fold among microcosms with different flow treatments in Expt 1 (Fig. 1a). On the other hand, cell-specific average Ara uptake was generally low (Fig. 1b) and even decreased with flow at lower Glc supply (Expt 2). These results are further supported by area-specific incorporation rates (Table 4) which have significant and opposing trends with flow for Glc and Ara, respectively. Decreasing Ara uptake at higher flow clearly supports the catabolite repression effect of Glc that we inferred from the MAR results at the level of the whole biofilm. At the microcosm level, patterns of uptake rates increase accordingly from the laminar to the turbulent flow treatment in case of Glc. For Ara, uptake rates calculated at microcosm level showed decreasing, but non-significant, trends from the laminar to the turbulent flow treatment. We attribute this mainly to the relatively low uptake rates for Ara which were difficult to measure at the level of the microcosm, and the much greater sensitivity with which Ara incorporation can be detected at the biofilm and cell level.

\section{Implications for stream ecosystems}

Differential uptake of Glc and Ara induced the conspicuous and consistent trends of Glc:Ara ratios at the single-cell and microcosm level (Fig. 1c,d). These data suggest that biofilm heterotrophs in fast flow satisfy their carbon demand primarily from labile compounds that are continuously supplied from the stream water. On the other hand, Ara:Glc uptake ratios indicate that biofilm heterotrophs in slow flow rely increasingly on less labile carbon compounds from the water column. Additionally, in slow flow, heterotrophs may also depend more on internal carbon sources, such as extracellular release from algae (Haack \& McFeters 1982, Kaplan \& Bott 1989, Jones \& Lock 1993). As in other reports, we found higher chl a concentrations in slow flow which would potentially allow a better supply of heterotrophs with algae-derived organic carbon (Biggs \& Gerbeaux 1993, Battin et al. 2003a). While the supply flux of carbon from the water column to the biofilm is unidirectional and downward in direction, algae as in- 
ternal carbon sources may be located at various biofilm depths, potentially leading to higher heterogeneity of substrate supply and thus dampening metabolic stratification. Compact biofilms as a structural adaptation to physical stress in fast flow on the one hand, and structural components such as channels and voids favouring advective transport in slow flow on the other hand, will both further accentuate the differences in metabolic stratification among the flow treatments.

Our findings on the fine-scale mechanisms underlying monomer uptake by microbial biofilms expand our understanding of DOC processing in streams. The fact that we found congruent patterns of monomer uptake from cells to microcosms makes us confident that our experimental findings can be extrapolated, at least in part, to stream ecosystems. Using dimensions of the microcosm setup, we can express uptake rates at the level of the microcosms (Table 3) as mass transfer coefficients, which then range from 0.11 to $0.42 \mathrm{~mm} \mathrm{~min}^{-1}$ for Glc and 0.005 to $0.036 \mathrm{~mm} \mathrm{~min}^{-1}$ for Ara. These estimates are about 1 order lower for Glc and 2 orders lower for Ara in comparison to data from monomer injections to natural streams (Kaplan \& Newbold 2003). These results are reasonable, given that there were no interstitial habitats in our microcosms, and monomer uptake was strictly restricted to the uppermost currentexposed biofilms. Importantly, the active surface area, a crucial parameter for estimation of mass transfer coefficients, is accurately determined in the microcosms, while in field injection experiments it is usually estimated from stream bottom surface area. Our findings from experimentally manipulated flow environments have important implications for natural streams where the spatial distribution of flow velocity in benthic habitats is inherently heterogeneous. In streams, biofilms exposed to high flow may predominantly take up labile DOC compounds; less labile compounds may be taken up locally in these same biofilms, and, more importantly, in the less stratified biofilms growing under low flow velocity. Thus, biofilm structural and functional diversity, which reflects flow heterogeneity in streams, may influence carbon cycling and its fate to downstream ecosystems.

Acknowledgements. This research was supported by grants from the Austrian Science Fund (P16935-B03), the European Science Foundation (COMIX, AI0004321) and the Land Niederösterreich to T.J.B.

\section{LITERATURE CITED}

Amon RMW, Benner R (1996) Bacterial utilization of different size classes of dissolved organic matter. Limnol Oceanogr 41:41-51

> Andreasen K, Nielsen PH (1997) Application of microautoradiography for the study of substrate uptake by filamen- tous microorganisms in activated sludge. Appl Environ Microbiol 63:3662-3668

Battin TJ, Kaplan LA, Newbold JD, Hansen CME (2003a) Contributions of microbial biofilms to ecosystem processes in stream mesocosms. Nature 426:439-442

Battin TJ, Kaplan LA, Newbold JD, Cheng X, Hansen CME (2003b) Effects of current velocity on the nascent architecture of stream microbial biofilms. Appl Environ Microbiol 69:5443-5452

Battin TJ, Kaplan LA, Findlay S, Hopkinson CS and others (2008) Biophysical controls on organic carbon fluxes in fluvial networks. Nat Geosci 1:95-100

Battin TJ, Luyssaert S, Kaplan LA, Aufdenkampe AK, Richter A, Tranvik L (2009) The boundless carbon cycle. Nat Geosci 2:598-600

$>$ Berggren M, Laudon H, Haei M, Ström L, Jansson M (2010) Efficient aquatic bacterial metabolism of dissolved lowmolecular-weight compounds from terrestrial sources. ISME J 4:408-416

Besemer K, Singer G, Limberger R, Chlup AK and others (2007) Biophysical controls on community succession in stream biofilms. Appl Environ Microbiol 73:4966-4974

> Beyenal H, Lewandowski Z (2002) Internal and external mass transfer in biofilms grown at various flow velocities. Biotechnol Prog 18:55-61

Biggs BJF, Gerbeaux P (1993) Periphyton development in relation to macroscale (geology) and microscale (velocity) limiters in two gravel-bed rivers, New Zealand. NZ J Mar Freshw Res 27:39-53

Characklis WG, Marshall KC (1990) Biofilms. Wiley, New York, NY

> Cole JJ (2007) Plumbing the global carbon cycle: integrating inland waters into the terrestrial carbon budget. Ecosystems 10:172-185

De Beer D, Kühl M (2001) Interfacial microbial mats and biofilms. In: Boudreau P, Jorgensen BB (eds) The benthic boundary layer, transport processes and biogeochemistry. Oxford University Press, Oxford, p 374-394

> De Beer D, Stoodley P, Lewandowski Z (1996) Liquid flow and mass transport in heterogeneous biofilms. Water Res 30: 2761-2765

Frazier SW, Kaplan LA, Hatcher PG (2005) Molecular characterization of biodegradable dissolved organic matter using bioreactors and $\left[{ }^{12} \mathrm{C} /{ }^{13} \mathrm{C}\right]$ tetramethylammonium hydroxide thermochemolysis GC-MS. Environ Sci Technol 39: 1479-1491

- Gantzer CJ, Rittmann BE, Herricks EE (1988) Mass transport of biodegradable materials to streambed biofilms. Water Res 22:709-723

> Görke B, Stulke J (2008) Carbon catabolite repression in bacteria: many ways to make the most out of nutrients. Nat Rev Microbiol 6:613-624

Gordon ND, McMahon TA, Finlayson BL, Gippel CJ, Nathan RJ (2004) Stream hydrology, an introduction for ecologists, 2nd edn. John Wiley, Chichester

Grady CPLJ, Daigger GT, Lim HC (1999) Biological wastewater treatment, 2nd edn. Marcel Dekker, New York, NY

> Haack TK, McFeters GA (1982) Microbial dynamics of an epilithic mat community in a high alpine stream. Appl Environ Microbiol 43:702-707

> Hansen SK, Rainey PB, Haagensen JAJ, Molin S (2007) Evolution of species interactions in a biofilm community. Nature 445:533-536

> Hertkorn N, Frommberger M, Witt M, Koch B, SchmittKopplin P, Perdue E (2008) Natural organic matter and the event horizon of mass spectrometry. Anal Chem 80: 8908-8919 
Jones SE, Lock MA (1993) Seasonal determinations of extracellular hydrolytic activities in heterotrophic and mixed heterotrophic autotrophic biofilms from two contrasting rivers. Hydrobiologia 257:1-16

Kaplan LA, Bott TL (1989) Diel fluctuations in bacterial activity on streambed substrata during vernal algal blooms effects of temperature, water chemistry, and habitat. Limnol Oceanogr 34:718-733

Kaplan LA, Newbold DJ (2003) The role of monomers in stream ecosystem metabolism. In: Findlay SEG, Sinsabaugh RL (eds) Aquatic ecosystems: interactivity of dissolved organic matter. Academic Press, San Diego, CA, p 97-119

Kim S, Kaplan LA, Hatcher PG (2006) Biodegradable dissolved organic matter in a temperate and a tropical stream determined from ultra-high resolution mass spectrometry. Limnol Oceanogr 51:1054-1063

Lee N, Nielsen PH, Andreasen KH, Juretschko S, Nielsen JL, Schleifer KH, Wagner M (1999) Combination of fluorescence in situ hybridization with microautoradiography - a new tool for structure-function analyses in microbial ecology. Appl Environ Microbiol 65:1289-1297

Lock MA, Wallace RR, Costerton JW, Ventullo RM, Charlton SE (1984) River epilithon: toward a structural-functional model. Oikos 42:10-22

Lyon DR, Ziegler SE (2009) Carbon cycling within epilithic biofilm communities across a nutrient gradient of headwater streams. Limnol Oceanogr 54:439-449

Madigan MT, Martinko J, Dunlap P, Clark DP, Brock TD (2008) Brock biology of microorganisms, 12th edn. Prentice Hall International, San Francisco, CA

Magasanik B (1961) Catabolite repression. Cold Spring Harb Symp Quant Biol 26:249-256

Manly BFJ (2006) Randomization, bootstrap and Monte Carlo methods in biology, 3rd edn. Chapman \& Hall, London

Editorial responsibility: Staffan Kjelleberg,

Sydney, New South Wales, Australia
Monod J (1942) Recherches sur la croissance des cultures bactériennes. $\mathrm{PhD}$ thesis, Hermann et Cie, Paris

Moran MA, Hodson RE (1994) Support of bacterioplankton production by dissolved humic substances from three marine environments. Mar Ecol Prog Ser 110:241-247

Picioreanu C, van Loosdrecht MCM, Heijnen JJ (2000) A theoretical study on the effect of surface roughness on mass transport and transformation in biofilms. Biotechnol Bioeng 68:355-369

Singer G, Besemer K, Hödl I, Chlup AK, Hochedlinger G, Stadler P, Battin TJ (2006) Microcosm design and evaluation to study stream microbial biofilms. Limnol Oceanogr Methods 4:436-447

Sun L, Perdue EM, Meyer JL, Weis J (1997) Use of elemental composition to predict bioavailability of dissolved organic matter in a Georgia river. Limnol Oceanogr 42:714-721

Thurman EM (1985) Developments in biogeochemistry: organic geochemistry of natural waters. Martinus Nijhoff and Dr W. Junk Publishers, Dordrecht

> Tranvik LJ, Höfle MG (1987) Bacterial growth in mixed cultures on dissolved organic carbon from humic and clear waters. Appl Environ Microbiol 53:482-488

Velji MJ, Albright LJ (1986) Microscopic enumeration of attached marine bacteria of seawater, marine sediment, fecal matter, and kelp blade samples following pyrophosphate and ultrasound treatment. Can J Microbiol 32:121-126

> Volk CJ, Volk CB, Kaplan LA (1997) Chemical composition of biodegradable dissolved organic matter in streamwater. Limnol Oceanogr 42:39-44

Wetzel RG (1992) Gradient-dominated ecosystems: sources and regulatory functions of dissolved organic matter in freshwater ecosystems. Hydrobiologia 229:181-198

Ziegler SE, Lyon DR, Townsend SL (2009) Carbon release and cycling within epilithic biofilms in two contrasting headwater streams. Aquat Microb Ecol 55:285-300

Submitted: May 19, 2010; Accepted: August 30, 2010

Proofs received from author(s): November 19, 2010 